\title{
Erratum to: Entrapment and Near Miss: A Comparative Analysis of Psycho-Structural Elements in Gambling Games and Massively Multiplayer Online Role-Playing Games
}

\section{Faltin Karlsen}

Published online: 25 May 2010

(C) Springer Science+Business Media, LLC 2010

\section{Erratum to: Int J Ment Health Addiction DOI 10.1007/s11469-010-9275-4}

There are two small errors in the article. On line 206 (page 5) there is a comma between the words gambling and machines that should not be there. On line 482 (page 11) the word "I" is replaced by the word "Introduction".

The online version of the original article can be found at http://dx.doi.org/10.1007/s11469-010-9275-4.

F. Karlsen $(\bowtie)$

The Norwegian School of Information Technology, Oslo, Norway

e-mail: fk@nith.no 